\title{
Advanced Microstructure Studies of an Austenitic Material Using EBSD in Elevated Temperature In-Situ Tensile Testing in SEM
}

\author{
Mattias Calmunger, Ru Peng, Guocai Chai, Sten Johansson and Johan Moverare
}

\section{Linköping University Post Print}

\section{Tweet}

N.B.: When citing this work, cite the original article.

Original Publication:

Mattias Calmunger, Ru Peng, Guocai Chai, Sten Johansson and Johan Moverare, Advanced Microstructure Studies of an Austenitic Material Using EBSD in Elevated Temperature InSitu Tensile Testing in SEM, 2014, Key Engineering Materials, (592-593), 497-500. http://dx.doi.org/10.4028/www.scientific.net/KEM.592-593.497

Copyright: Trans Tech Publications http://www.ttp.net/

Postprint available at: Linköping University Electronic Press http://urn.kb.se/resolve?urn=urn:nbn:se:liu:diva-97015 


\title{
Advanced microstructure studies of an austenitic material using EBSD in elevated temperature in-situ tensile testing in SEM
}

\author{
Mattias Calmunger ${ }^{1, a}$, Ru Lin Peng ${ }^{1, b}$, Guocai Chai ${ }^{1,2, c}$, Sten Johansson ${ }^{1, d}$ and \\ Johan Moverare ${ }^{1, e}$
}

${ }^{1}$ Division of Engineering Materials, Department of Management and Engineering, Linköping University, SE-58183 Linköping, Sweden

\author{
${ }^{2}$ AB Sandvik Materials Technology R\&D center, SE-81181 Sandviken, Sweden \\ amattias.calmunger@liu.se, ${ }^{b}$ ru.peng@liu.se, ${ }^{c}$ guocai.chai@sandvik.com, ${ }^{d}$ sten.johansson@liu.se, \\ johan.moverare@liu.se
}

Keywords: Austenitic stainless steel, electron backscatter diffraction, in-situ tensile test, Schmid factor, grain size and slip system.

\begin{abstract}
In this study an advanced method for investigation of the microstructure such as electron backscatter diffraction (EBSD) together with in-situ tensile test in a scanning electron microscope (SEM) has been used at room temperature and $300^{\circ} \mathrm{C}$. EBSD analyses provide information about crystallographic orientation in the microstructure and dislocation structures caused by deformation. The in-situ tensile tests enabled the same area to be investigated at different strain levels. For the same macroscopic strain values a lower average misorientation in individual grains at elevated temperature indicates that less residual strain at grain level are developed compared to room temperature. For both temperatures, while large scatters in grain average misorientation are observed for grains of similar size, there seems to be a tendency showing that larger grains may accumulate somewhat more strains.
\end{abstract}

\section{Introduction}

Advanced austenitic materials such as Sanicro 25 are often used as structural materials for applications at elevated temperature. Therefore it is of interest to study how the microstructure responds to deformation at elevated temperatures using information from in-situ tensile test in a scanning electron microscope (SEM) together with an electron backscatter detector (EBSD). The in-situ tensile tests enable the same area at different strain levels to be investigated. To identify crystal structure and crystallographic orientation the EBSD technique uses Kikuchi patterns together with a database and this technique can be used for lattice orientation and grain size determination. From distribution and amount of low angle grain boundaries (LAGB) in the material, strain variations from external forces as well as from the manufacturing process can be gathered $[1,2]$.

In-situ tensile deformation investigations in SEM have been performed by other research groups, studying microstructural changes, deformation and fracture mechanisms of different materials [3-5].

In this study in-situ tensile testing was performed on Sanicro 25 at two different temperatures. An investigation of the influence temperatures on the deformation behaviour was performed using the EBSD technique. Fracture behaviour will also be discussed.

\section{Material and experimental details}

The material used in this study is a newly developed austenitic stainless steel named Sanicro 25, supplied by AB Sandvik Materials Technology, see Table 1 for nominal composition in wt\%.

Table 1. The nominal composition of Sanicro 25.

\begin{tabular}{c|ccccccccccc} 
Element & $\mathrm{C}$ & $\mathrm{Si}$ & $\mathrm{Mn}$ & $\mathrm{Cr}$ & $\mathrm{Ni}$ & $\mathrm{W}$ & $\mathrm{Co}$ & $\mathrm{Cu}$ & $\mathrm{Nb}$ & $\mathrm{N}$ & $\mathrm{Fe}$ \\
\hline $\mathrm{Wt} \%$ & 0,1 & 0,2 & 0,5 & 22,5 & 25 & 3,6 & 1,5 & 3,0 & 0,5 & 0,23 & Bal.
\end{tabular}


The samples were cut out to a thickness of $1,0 \mathrm{~mm}$ from a tube with the loading direction along the axial direction of the tube, using an electronic discharge wire saw to minimize the effects of surface hardening. Both sides of the samples were carefully ground and one side further prepared for EBSD analysis using polishing. The final thickness of the specimens was 0,9 and $0,7 \mathrm{~mm}$ for room temperature and elevated temperature test respectively. To enable the in-situ tensile test and EBSD investigations a specially designed tensile test stage with heating ability from Gatan was mounted to a HITACHI SU-70 FEG-SEM equipped with an OXFORD electron backscatter diffraction (EBSD) system and HKL software.

The in-situ tensile test was carried out at two temperatures, room temperature (RT) and $300^{\circ} \mathrm{C}$, at two strain rate, $0,2 \mathrm{~mm} / \mathrm{min}$ for the RT specimen and $0,1 \mathrm{~mm} / \mathrm{min}$ for the $300^{\circ} \mathrm{C}$ specimen. Heat was introduced into the specimen via the grips so before the testing could start the specimen temperature was measured using an external thermocouple. None of the specimens were tested to fracture since too high plastic deformation introduces surface intrusions affecting the EBSD negatively.

\section{Results and discussion}

The in-situ tensile testing reveals that an increase in temperature gives a lower yield stress level for Sanicro 25. Fig.1 shows how the engineering stress-strain curve was affected when the temperature increased. The Young's modulus indicated by the slope of the linear part of the curves can be affected by larger uncertainties in strains which were derived from stress induced changes of distance between markers in the microstructure. Based on regular tensile tests the Young's modulus should be lower at $300^{\circ} \mathrm{C}$ than at RT.

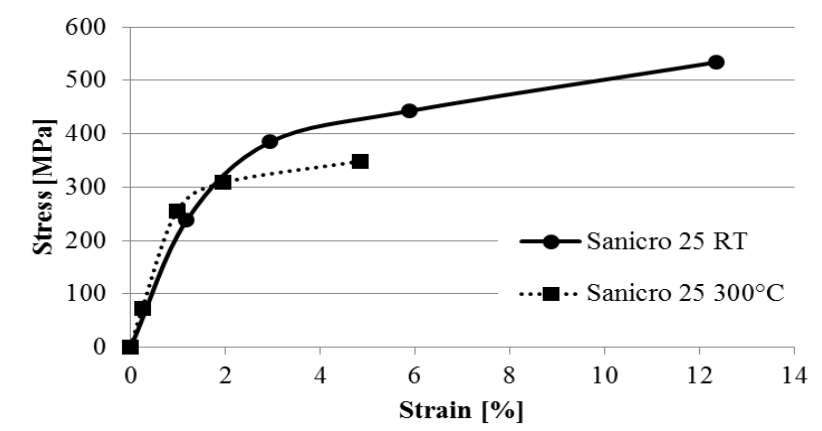

Figure 1. Engineering stress-strain curve at room temperature (RT) and $300^{\circ} \mathrm{C}$.

The macroscopic differences of the non-linear part of the stress-strain curves between the two temperatures, observed in Fig.1, can be explained by different behaviour on a microscopic scale. In a plastically deformed material, local misorientations are related to plastic strain. By taking the average value of misorientations measured between all neighboring points in a grain, an average misorientation angle providing an indication of plastic strain in the grain was obtained [6]. To compare different loading conditions grain average misorientation (GAM) maps and inverse pole figures (IPF), that shows crystallographic orientation, have been generated. The whole analysed area covers around 800 and 400 grains for the $\mathrm{RT}$ and the $300^{\circ} \mathrm{C}$ specimens respectively. Due to the space limitation only a smaller part of the analysed area for selected strain levels is shown here in Fig.2. As can be seen, GAM in general develops for all grains with increasing macroscopic strains, which is also confirmed by the IPF. Both Fig. 2 and linear regression of the whole examined area reveal that under higher macroscopic strains larger grains seem to show a somewhat higher degree of GAM than smaller ones. This means that more plastic strains may be accumulated in larger grains than in smaller grains, as predicted by the Hall-Petch equation. Further experiments are needed to support this. However, it should be pointed out here that the scatter in GAM is large among grains of similar size (obvious from Fig. 2), because the grain orientation with respect to the loading direction and constraints from the surrounding grains are also important for the plastic deformation behaviour of the grains. From statistics, RT shows a higher degree of GAM than $300^{\circ} \mathrm{C}$ for similar strain levels. At elevated temperature, dislocation movement can be faster than at RT 
due to thermal activation but also affected by diffusion controlled processes like dynamic strain ageing. The different strain rates can therefore give a small contribution to this observed effect.

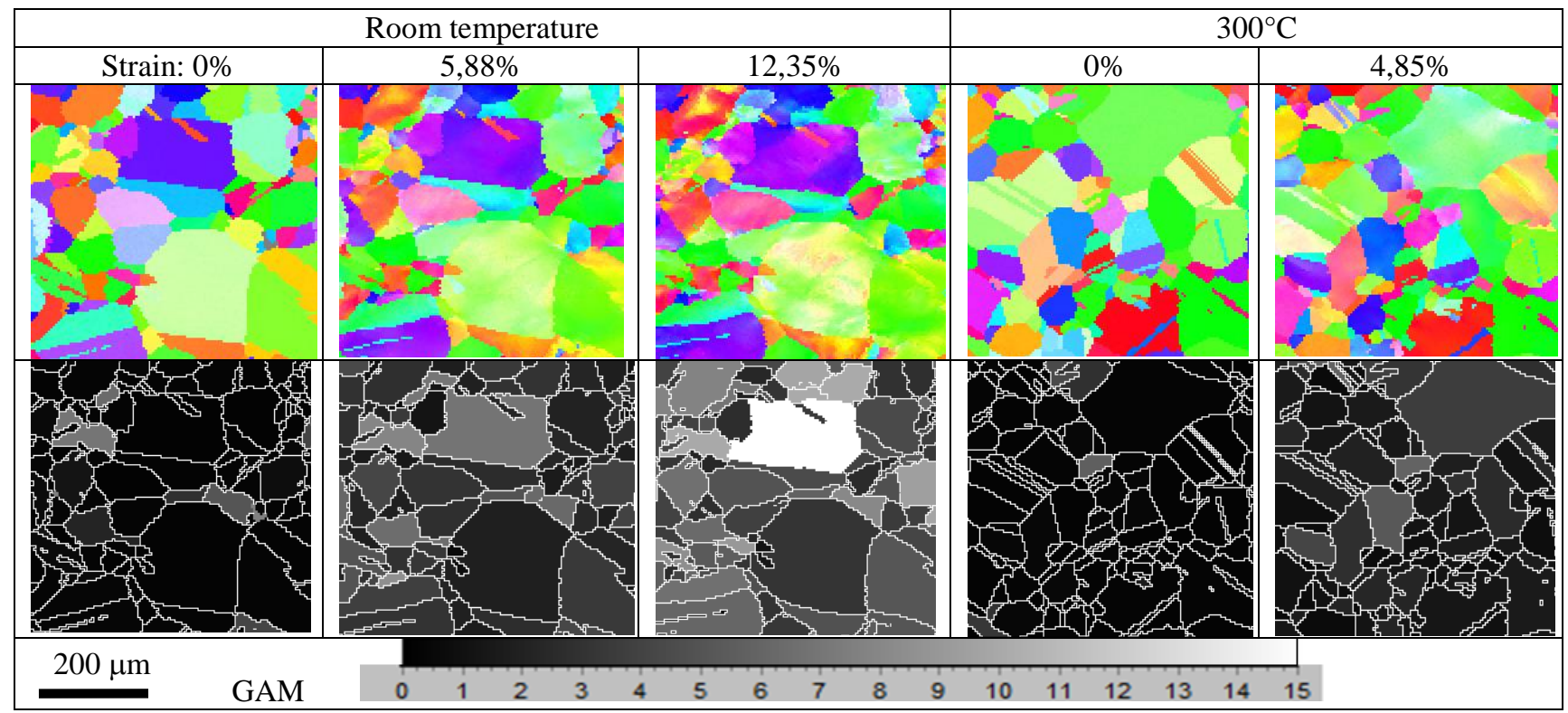

Figure 2. IPF (row 1) and grain average misorientation maps (row 2) with scale bars (row 3). The IPF maps correspond to the legend in Fig. $3 \mathrm{f}$ ). The loading axis lies horizontally.

On a microscopic level the deformation in the grains is dependent on the Schmid factor (SF) that affects the resolved shear stress acting on a certain slip system. A high SF value in a slip system increases the probability of activating dislocation movement in the slip system due to a higher resolved shear stress, resulting in plastic deformation. This is also dependent on the neighbouring grains SF and which slip systems that are active in those grains. SF for different slip systems can be derived from the EBSD analysis data, see for example Table 2 where grains 2 and 4 are indicated in Fig. 3. Grain 4 showing cracks along the active slip system near $42^{\circ}$ that is the (IIII)[IIO] with the

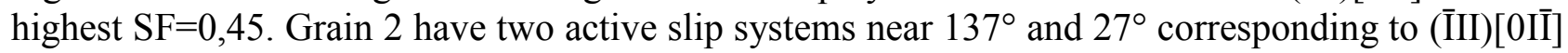
with $\mathrm{SF}=0,45$ and (III) [III0] with $\mathrm{SF}=0,40$ respectively.

In addition to deformation, the EBSD-mapping can also generate information for discussion of fracture behaviour. Fig. 3 a) to d) show how the LAGB (with 2-6 angle) distribution change with deformation, $\varepsilon=1,18 \%$ to $\varepsilon=12,35 \%$ strain at RT, and follows the reorientation displayed by the colourful IPF mapping. At 12,35\% strain small cracks have appeared in Fig.3 e), related to the severe slip bands from dislocation movements on multiple slip systems in both grain 4 and the surrounding grains 2, 3 and 5. The observed cracks in Fig. 3 e) initiate and propagate along the slip systems with highest SF according to Table 2.

Table 2. Active slip systems and SF and slip trace $\left[{ }^{\circ}\right]$ at $0 \%$ and $12,35 \%$ strain

\begin{tabular}{|c|c|c|c|c|c|}
\hline Grain & Macroscopic strain & Slip system & SF & Pos. slip trace & Neg. slip trace \\
\hline \multirow{6}{*}{4} & \multirow{3}{*}{$0 \%$} & $(\overline{\bar{I}} \mathrm{II})[\mathrm{II} 0]$ & 0,44 & 133 & 47 \\
\hline & & $(\overline{\mathrm{I}} \mathrm{II})[0 \overline{\mathrm{I}} \mathrm{I}]$ & 0,43 & 133 & 47 \\
\hline & & $(\overline{\mathrm{III}})[\overline{\mathrm{I}} \mathrm{I} \mathrm{O}]$ & 0,35 & 65 & 115 \\
\hline & \multirow{3}{*}{$12,35 \%$} & $(\overline{\mathrm{IIII}})[\mathrm{IIO}]$ & 0,45 & 138 & 42 \\
\hline & & $(\overline{\mathrm{IIII}})[0 \overline{\mathrm{II}}]$ & 0,40 & 138 & 42 \\
\hline & & 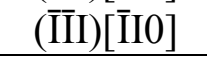 & 0,32 & 69 & 111 \\
\hline \multirow{6}{*}{2} & \multirow{3}{*}{$0 \%$} & $(\overline{\mathrm{IIII}})[0 \mathrm{I} \overline{\mathrm{I}}]$ & 0,47 & 46 & 134 \\
\hline & & $(\mathrm{III})[0 \overline{\mathrm{II}}]$ & 0,38 & 96 & 84 \\
\hline & & 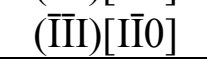 & 0,37 & 24 & 156 \\
\hline & \multirow{3}{*}{$12,35 \%$} & $(\overline{\mathrm{III}})[0 \mathrm{III}]$ & 0,45 & 43 & 137 \\
\hline & & $(\mathrm{III})[0 \overline{\mathrm{II}}]$ & 0,35 & 98 & 82 \\
\hline & & $(\overline{\mathrm{IIII}})[\mathrm{I} \overline{\mathrm{I}} \mathrm{O}]$ & 0,40 & 27 & 153 \\
\hline
\end{tabular}




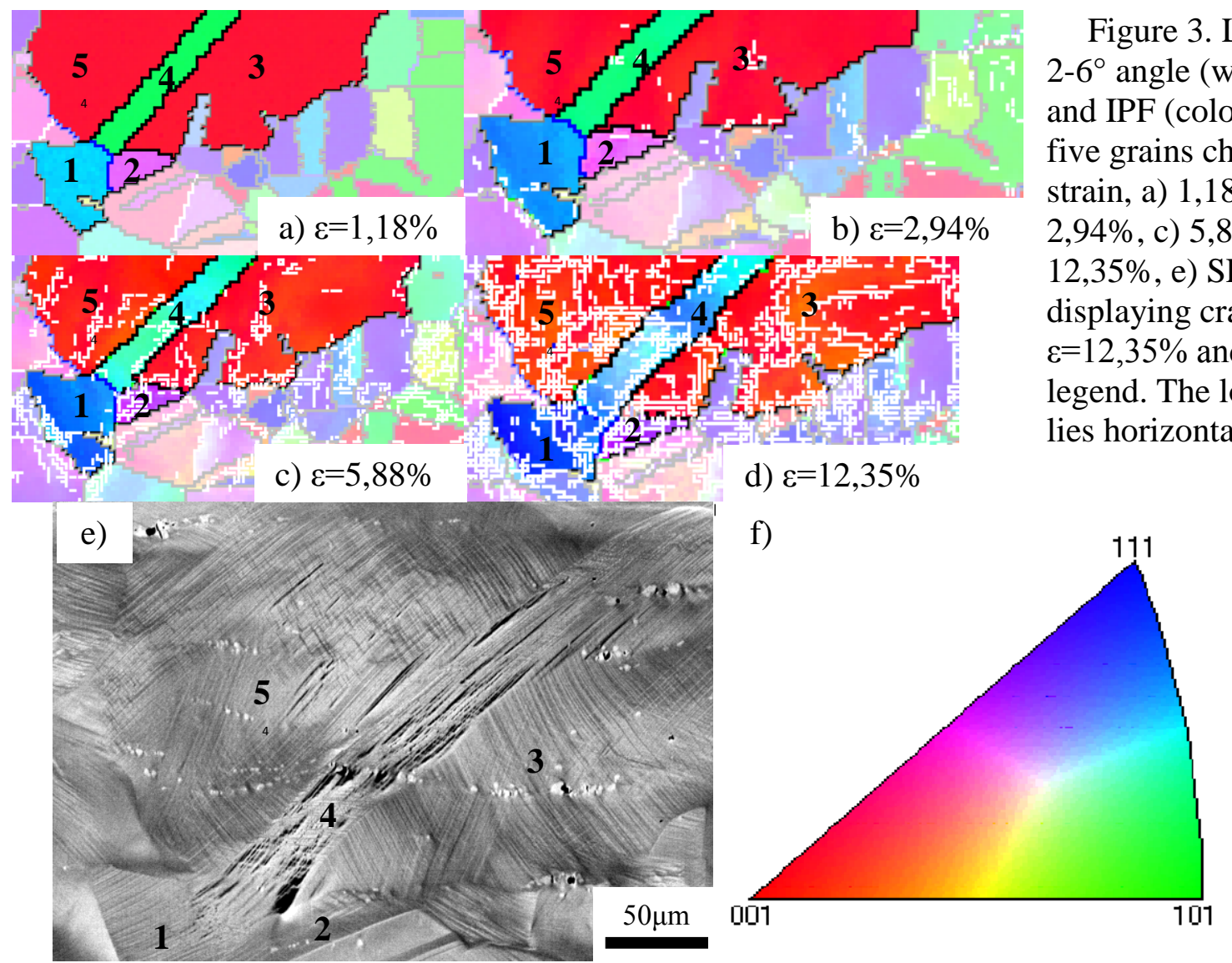

\section{Conclusion}

The analysis from in-situ tensile test at RT and $300^{\circ} \mathrm{C}$ in a SEM together with EBSD in Sanicro 25 has shown that, larger grains may tend to accumulate more local plastic strain for the same macroscopic strain values at both temperatures. Somewhat higher plastic strains at grain level can be obtained at RT than at elevated temperature for the same macroscopic strain value. Cracks initiate and propagate along the slip system(s) with the highest SF at RT.

\section{Acknowledgements}

Present study was financially supported by AB Sandvik Materials Technology in Sweden and the Swedish National Energy Administration through the Research Consortium of Materials Technology for Thermal Energy Processes, Grant No. KME-501. Agora Materiae and Strategic Faculty Grant AFM (Faculty grant SFO-MAT-LiU\#2009-00971) at Linköping University is also acknowledged.

\section{References}

[1] A. J. Schwartz, M. Kumar, B. L. Adams and D.P. Field: Electron Backscattering Diffraction in Material Science, Springer Science + Business Media, New York (2009).

[2] M. Kamaya: Mater Charact. Vol. 66 (2012), p. 56

[3] H. Bjerkaas, S.K. Fjeldbo, H.J. Roven, J. Hjelen, R. Chiron and T. Furu: Mater. Sci. Forum Vol. 519-521 (2006), p. 809

[4] N. Jia, R. Lin Peng, G.C. Chai, S. Johansson and Y.D. Wang: Materials Science and Engineering A Vol. 491 (2008), p. 425

[5] M. Lundberg, M. Calmunger and R.L. Peng: ICF13 (2013), S12-038

[6] R. Yoda, T. Yokomaku and N. Tsuji: Mater. Charact. Vol. 61 (2010), p. 913 